\title{
Healthcare is Changing, while Medical Training is Lagging Behind
}

\author{
Monique WM Jaspers* \\ Department Medical Informatics, Dean of Educational Institute Medical Informatics, Amsterdam Public Health Research Institute, \\ Amsterdam, Netherlands
}

*Corresponding author: Monique WM Jaspers, Department Medical Informatics, Dean of Educational Institute Medical Informatics, Amsterdam Public Health Research Institute, Amsterdam, Netherlands

\begin{tabular}{|c|c|}
\hline ARTICLE INFO & ABSTRACT \\
\hline $\begin{array}{l}\text { Received: 㗀 January 24, } 2020 \\
\text { Published: 蔧 February 06, } 2020\end{array}$ & $\begin{array}{l}\text { Citation: Monique WM Jaspers. Healthcare is Changing, while Medical Training is } \\
\text { Lagging Behind. Biomed J Sci \& Tech Res 25(3)-2020. BJSTR. MS.ID.004196. }\end{array}$ \\
\hline
\end{tabular}

\section{Editorial}

Healthcare is changing. More than ever, the relationship between the patient and his caregiver is focused on optimizing the quality of life of the patient. In addition to treating patients and diseases, healthcare providers will play an increasingly important role in disease prevention, quality of life and maintenance of the functioning of the patient. This requires a holistic approach to the patient. Networks of healthcare professionals which take the needs of the patient as a starting point are crucial for this. Information technology changes the processes within and outside healthcare institutions: treating physicians and patients have easy contact via digital technology. In health care there is also a growing emphasis on self-management and patient empowerment to increase the quality and effectiveness of treatment outcomes. Online support is becoming more common in-patient self-management, especially in the chronically ill. Technological developments also make it possible to exchange, store, disclose and process large amounts of digitized data directly via the internet.

The technology also offers possibilities for new applications and new analysis techniques by which large quantities of medical data can be searched for patterns. The Internet of Things, artificial intelligence, big data analysis combined with wearables and home diagnostics, ensures that patients (and their caregivers) can quickly get an idea of their medical situation. The knowledge obtained from big data analysis can be returned to healthcare practice in the form of clinical guidelines, audit and feedback and automated clinical decision-making systems. With the introduction and further development of smartphones, a world has also opened up for collecting information about behavior, lifestyle and health.
This information can be used to remotely monitor the progress of a patient on an individual level. Subsequently, this offers possibilities for prevention and recognizing disorders before they reveal themselves. Moreover, mobile health, in short mHealth, offers opportunities for new ways of delivering care to patients, for example through online contact, which can lead to even better outcomes of care and to its increasing affordability, such as in mental health care. mHealth techniques for example offer a way to improve the daily life of the client through (digital) monitoring and treating of symptoms.

The purpose of this is to help the client collect the information that matters in his or her life. This puts the client much more at the center of their own treatment. Digital access to a patient's medical file is a logical extension of this and has several substantive advantages: it can benefit understanding of the disease, the quality of life and therefore the care. Patients and clients, however, are increasingly concerned about how healthcare institutions and their healthcare providers handle their personal data. And so, it is important for healthcare organizations to let them know that the privacy of their patients and clients is in safe hands with them. New security rules an data protection regulation is introduced. In short: the digitization of health care is irreversible, and with eHealth, the use of internet technology for prevention and health care has become an important spearhead.

Healthcare professionals are thus increasingly confronted with eHealth and health technology in their work and must be able to critically consider these developments and make informed decisions in the light of the advantages and disadvantages of these 
new developments. Their function will change, not only in skills but also in the role they play in the healthcare system in which they will work together, supported by technology. Yet, there is a gap between what healthcare professionals face in the workplace regarding the introduction of new technologies, and what they have learned during their training. It is therefore of crucial importance that eHealth and healthcare technology become part of educational landscape of future healthcare professionals.

These future healthcare professionals should be able:

a) To recognize that medical technological developments can contribute to improving patient care

b) To assess health technological developments for their added value in improving patient care; - to know the limits of their own knowledge and skills in the field of healthcare technology

ISSN: 2574-1241

DOI: 10.26717/BJSTR.2020.25.004196

Monique WM Jaspers. Biomed J Sci \& Tech Res

(c) 9 This work is licensed under Creative

Submission Link: https://biomedres.us/submit-manuscript.php c) To recognize the importance of collaboration with other (care) professionals and companies in the field of technological innovations

d) To identify opportunities for existing and new technological innovations, $\mathrm{t}$ - $\mathrm{o}$ act accordingly and dare to take responsible risks and

e) Be aware that different steps are needed to bring about change with healthcare technology.

Medical Schools should take these learning goals into account in redesigning their curricula. Only then we can hope for efficient use of technological innovation in the healthcare domain with the ultimate aim to improve the accessibility, quality and affordability of healthcare.

$\begin{array}{ll}\text { BIOMEDICAL } & \text { Assets of Publishing with us } \\ \text { RESEARCHES } & \text { - Global archiving of articles } \\ & \text { - Immediate, unrestricted online access } \\ & \text { - Rigorous Peer Review Process } \\ & \text { - Anttps://biomedres.us/ }\end{array}$

